\title{
Analysis on Influencing Factor of 3D Printing Technology on Cultural and Creative Products
}

\author{
Hui Xu \\ Yinxing Hospitality Management College of CUIT, Shichuan, Chengdu, 611743
}

Keywords: 3D printing technology; cultural and creative products; influencing factors; legal constraints; intellectual property rights

\begin{abstract}
D printing technology is a new technology emerging in recent years. It has the excellent function of rapidly generating model or part entity, which can play a role in promoting and coordinating the development of various industries. This paper analyzes the influencing factors of 3D printing technology on the field of cultural and creative products.
\end{abstract}

\section{Introduction}

Cultural and creative products are cultural and creative industries and related products. It is cultural and creative manufacturing industry driven by creativity based on the original traditional cultural industries and represents high-level product formed by matching consumption structure after productivity has developed in to a certain higher degree. Current cultural and creative products are combined with the most advanced 3D printing technology. The latter can achieve the rapid prototyping and rich creative ideas and meet the design and production requirements of the cultural and creative products. Therefore, the actual impact of 3D printing technology on the cultural and creative products is very profound.

\section{Basic Theory of 3D Printing Technology}

3D printing technology is mainly based on the computer 3D design model, mainly through software separate discrete and numerical control forming system, with hot nozzle, laser beam, and so on to pile and bond special materials including ceramics, metal powde, plastic resin, and even cell tissue, and finally to stack for molding manufacture to generate new physical product.

From the perspective of technical application connotation, 3D printing is a new application technology formed by converting 3D entities into a number of 2D planes, and then piling and processing materials layer by layer on the basis of traditional inkjet printing. Therefore, 3D printing and inkjet printer are closely related. With special metal materials and plastic ink, 3D printing technology is more advanced than inkjet printing. It is controlled by computer to pile special materials layer by layer, and finally physical model of three-dimensional structure is printed, of which each layer can be viewed as the plane printing, namely 3D printing effect formed by multiple planar printing layer.

According to the current technological progress, 3D printing technology is also constantly expanding its own technical connotation. Objectively, it has extended a number of scientific and cutting-edge technical fields, for example, information technology, which includes 3D image processing and digital printing technology, and relevant indicators of 3D printing technology can be realized by defining the model printing process and automatically controlling the direction of printing equipment. In addition, it is precision printing equipment, which is based on 3D printing to generate high-precision printing products around the "superposition of each layer" processing. It has relatively high requirements for precision and stability of printing equipment. Finally, it is materials science, which has carried out special treatment for raw materials of 3D printing, such as powder, liquefaction, silting materials, etc., which are quite common. In the process of product design and production, these materials need to be reintegrated after becoming finished products, highlighting their physical and chemical properties. 
In general, 3D printing technology is currently additive manufacturing technology based on different forms of change. The core technical problem it studies is the 3D object creation process under the background of continuous hierarchical manufacturing technology. It is based on single-layer 2D printing to add the third z-axis dimension continuously, just like making a thousand-layer cake, but it is more delicate, so its printing materials and forming principle are more special and creative [1].

\section{Illustration of Influencing Factors of 3D Printing Technology on Cultural and Creative Products}

Currently, 3D printing technology has been regarded as the source of the "third industrial revolution", which indicates that this technology is subversive compared with the traditional technology. It has high-precision industrial level and is different from ordinary plane printing software facilities. Its production materials and output equipment are more novel and cool, favored by professionals in various industries.

In the field of cultural and creative product design and manufacturing, such as digital publishing, tourism products, animation film and TV, and the field of designing a variety of personalized life craft products, 3D printing technology are applied in them currently, with close relationship and mutual promoting effect. Many cultural and creative design ideas that cannot be realized in the past can come true with the support of 3D printing technology. This makes the design and production of cultural and creative products more prosperous. It also shows that $3 \mathrm{D}$ printing technology has a significant impact on the field of cultural and creative industries. About the influence factors, there are four aspects to be briefly introduced in the following.

\subsection{Design concept}

3D printing technology offers a new concept of manufacturing layer by layer, so it is quite different from plane design in terms of design. It is not an exaggeration to say that it is a subversion of traditional design. In fact, this is a novel mould manufacturing concept. Its forming scheme is freer, which infinitely expands the designer's design concept and creative thinking, making the designer bolder in the design process with more novel ideas. 3D printing is not the patent of designer. Its influence on ordinary users is great, which cannot be ignored, for example, it really opens the DIY era in the field of design, and general design lovers also can flexibly use 3D printer, with the 3D model resources downloaded online to take free 3D cultural and creative product design, which virtually stimulates ordinary design enthusiasts' interest and ability, lets them unconstrainedly exert their own imagination, realize 3D printing, and become the ideal designers and 3D cultural and creative product makers. Therefore, under the influence of 3D printing technology, the design concept and design of cultural and creative products have changed dramatically. It pays more attention to personalization, popularization and liberalization.

\subsection{Design mode of cultural and creative industry}

3D printing technology has changed the design mode of traditional cultural and creative industries, for example, in the field of clothing brand design, a brand enterprise wants to sell commemorative T-shirts in a community. First of all, the clothing brand will purchase a advertising board at community website, then make its own brand's electronic sales platform linked on the website, which provides basic T-shirt design templates, encouraging the community members to download the template and make DIY design, and finally it will collect community members' ideas for periodic comparison, adopt the ideas given by those ranking top, and conduct the T-shirt production manufacturing and sales. This attribute of 3D printing technology attracts the designers from the public to participate in the design, which has a certain degree of popularity. In addition, its design cost is low and its communication and sharing speed is fast, which can reduce its own design cost on the basis of giving full play to the mass design, as well as can better meet the personalized and differentiated needs of the public. Currently, Uniqlo has such a popular design idea, combined with 3D printing technology to produce mass creative products, which has a good sales 
performance.

\subsection{Modality of cultural and creative industry}

Currently, 3D printing technology is maturely advancing. Its printing design and supporting materials are also developing towards low cost. In the future, 3D printing technology is bound to be as popular as personal computers. Therefore, the continuous enrichment and innovation of the technology in this industry is an improvement of the new culture industry. First, the cultural and creative products should form a civilian lifestyle. For example, currently, more and more 3D studios have appeared on the market, and its function is richer and richer, from bareheaded photo, photo sticker in the past to souvenirs, three-dimensional wedding photos, holographic images and so on now. The photo services provided by it have been have more taste, and lifestyle. Certainly, 3D home gallery is also a new service project derived from the concept of 3D printing technology. It can design and produce 3D furniture products according to consumers' ideas, which is very considerate and humanized.

To sum up, the cultural and creative industry has already had a variety of influence factors on the modality of various industries in the society, but in fact, it is not limited to this. With the gradual application of 3D printing technology and its popularization, the efficiency of the product will be considered in the industry, in combination with the wide application, design and manufacture of computer technology contents including the Internet, big data and cloud computing; the three form the best integrated 3D service platform, to satisfy the real demand of integrating resources under the background of production and science research. This has greatly improved the design and creation capacity as well as production cycle of cultural and creative products, making the implementation efficiency of its production process comprehensively optimized [2].

\subsection{Intellectual property of cultural and creative industry}

Intellectual property is one of the important factors in the cultural and creative industry. The emergence and wide application of 3D printing technology will certainly involve the intellectual property of cultural and creative industry. Driven by the continuous innovation and development of 3D printing technology, the definition of some innovative intellectual property rights in the design and manufacture of cultural and creative products has become more complicated, and the protection of intellectual property rights has become more difficult. It needs to be clearly defined by laws and regulations, with the dynamic monitoring of the development of the industry.

As we all know, the core characteristic of 3D printing technology is allowing individuals or organizations to easily implement the process of "integration of design and production", belonging to a new DIY model in the manufacturing industry with high freedom. Such concept also can make the ideas of cultural and creative field realized and its products become more popular. However, the individualized design and production may bring a great impact on the protection of intellectual property rights and induce unimaginable collective piracy in an unconscious society. For example, it is possible to infringe upon the rights of obligee's patent right, copyright in literary creation, trademark right and other related rights. However, there are no laws that directly restrict individuals from designing and manufacturing cultural and creative products through 3D printing technology, which makes the development of the industry embarrassing. Some common problems such as 3D digital model and 3D printing technology are likely to occur with personal design and manufacturing infringement. The existence of such patent barrier will affect the cultural and creative industry for a long time.

For example, the emergence of 3D printing technology has an impact on the manufacturing technology in the field of design and manufacture of cultural and creative products, because 3D printing itself has the general property of manufacturing technology, and it is naturally associated with patents. Therefore, in the design process of 3D printing technology, 3D printing equipment not only provides materials and technology, but also establishes 3D digital model to provide design and manufacturing space for direct users. At present, the development momentum of 3D printing technology in the field of cultural and creative product design and production is explosive. It meets the designer's creative design and printing needs, making it difficult for designers to get rid of 3D 
printing design products. However, this kind of design and production lacks targeted guidelines for right protection, which means that $3 \mathrm{D}$ printing design may be suspected of infringement, and its protection process is relatively complex. For example, it infringes patents, copyright and even trademark rights. Therefore, it can be understood that the design and production of cultural and creative products by using 3D printing technology must have a clear purpose of use behavior. If it is for personal use, it may define its infringement behavior according to the degree of damage caused by the cultural and creative products to the right holder. Thus, in general, 3D printing technology has a great impact on the existing patent law of cultural and creative products. It is reflected in not only the level of technical protection, but also the level of industrial patent infringement judgment, which makes the relationship between 3D printing technology and cultural and creative products more complicated [3].

\section{Conclusion}

In this paper, many influence factors of 3D printing technology on the field of cultural and creative products are emphatically discussed, with detailed interpretation and analysis in combination with the actual situation. It can be seen that it has both positive promotion effect and negative constraint effect on the field of design and production of cultural and creative products. People should take an objective view of this issue from a neutral standpoint, constantly optimize and improve the application techniques and conditions of 3D printing technology in the cultural and creative industry, pay attention to its legal authority constraints and properly, and well handle various influence factors.

\section{References}

[1] Wang Lei. Development and application of 3D printing technology. Internal combustion engine and accessories, 2017(22):144-146.

[2] Jia Pindi, Tai Yixuan. Innovative design of creative cultural products based on 3D printing technology. Packaging world, 2017(3):126-128.

[3] Yang Cheng. On the impact of 3D printing technology on the cultural and creative industry. Art technology, 2015(9):33-33. 